\title{
Precariedad, crisis y nuevas miradas sobre el Estado. Condiciones de trabajo en el ámbito teatral platense antes y durante la pandemia
}

\author{
Precariedade, crise e novos olhares sobre o Estado \\ Condições de trabalho no teatro de La Plata antes e durante a pandemia \\ Precariousness, crisis and new views about the State \\ Labor conditions in La Plata theater before and during the pandemic
}

\author{
Mariana del Mármol ${ }^{1}$ \\ Juliana Díaz ${ }^{2}$
}

\begin{abstract}
Resumen
En este artículo abordaremos el caso del teatro independiente de la ciudad de La Plata (Buenos Aires, Argentina) con el objetivo de describir y analizar cómo impactó la crisis producida a partir la pandemia del COVID 19 y la medida de Aislamiento Social Preventivo y Obligatorio decretada por el gobierno nacional en los procesos de identificación de los/as teatristas como trabajadores/as, su organización colectiva para enfrentar la situación de emergencia y sus relaciones de articulación y demanda respecto de los organismos del Estado dedicados a la promoción y protección de la cultura.

El trabajo surge como parte de dos investigaciones paralelas y en diálogo que abordan problemas en torno al trabajo artístico en La Plata dentro de los últimos cinco años. Los datos que analizamos en este caso provienen del trabajo de campo realizado antes del ASPO; de observaciones y análisis documental realizadas en este último período, utilizando los dispositivos tecnológicos que tenemos a nuestro alcance y de una encuesta no probabilística impulsada por una organización de Profesores/as de Artes Escénicas Autogestivas recientemente creada en la ciudad, cuyo diseño, procesamiento y análisis de datos estuvo a cargo de una de las autoras de este artículo. Todo esto lo hemos puesto en diálogo con bibliografía afín a la temática laboral en general y del trabajo artístico en particular.
\end{abstract}

Palabras claves: crisis; precariedad; políticas culturales; teatro independiente platense; trabajo artístico

\section{Resumo}

Neste artigo abordaremos o caso do teatro independente da cidade de La Plata (Buenos Aires, Argentina) com o objetivo de descrever e analisar como a crise produzida a partir da pandemia COVID 19 e a medida de Isolamento Social Preventivo e Obrigatório (ASPO) decretada pelo governo nacional, impactou nos processos de identificação dos atores teatrais como trabalhadores, sua organização coletiva para o enfrentamento da situação de emergência e sua articulação e cobrança de relações com os órgãos do Estado voltados à promoção e proteção do cultura.

A obra surge como parte de duas investigações paralelas e em diálogo que abordam problemas em torno do trabalho artístico em La Plata nos últimos cinco anos. Os dados que analisamos, neste caso, vêm do trabalho de

\footnotetext{
${ }^{1}$ Becaria posdoctoral del Programa de Retención de Doctores de la Universidad Nacional de La Plata (Instituto de Investigaciones en Humanidades y Ciencias Sociales, UNLP/CONICET), Ayudante Diplomada en la cátedra de Etnografía I (Licenciatura en Antropología, Facultad de Ciencias Naturales y Museo, UNLP); marianadelmarmol@gmail.com.

${ }^{2}$ Becaria doctoral de la Comisión Nacional de Investigaciones Científicas y Técnicas en el Laboratorio de Estudios en Sociología y Economía del Trabajo (Instituto de Investigaciones en Humanidades y Ciencias Sociales, UNLP/CONICET) y adscripta en el taller Estudios sociológicos del mundo del trabajo (Licenciatura en Sociología, Facultad de Humanidades y Ciencias de la Educación, UNLP); julianadiaz345@gmail.com.
} 
campo realizado antes da ASPO; de observações e análises documentais realizadas neste último período, recorrendo aos dispositivos tecnológicos de que dispomos e de um inquérito não probabilístico promovido por uma organização de Professores de Artes Performativas Autogeridas recentemente criada na cidade, cujo desenho, processamento e análise os dados ficaram a cargo de um dos autores deste artigo. Colocamos tudo isso em diálogo com a bibliografia relacionada ao tema do trabalho em geral e do trabalho artístico em particular.

Palavras-Chave: crise; precariedade; políticas culturais; teatro independente de La Plata; trabalho artístico

\begin{abstract}
In this article, we will address the case of the independent theater in La Plata (Buenos Aires, Argentina) to describe and analyze how the crisis produced by the COVID 19 pandemic and the Preventive and Obligatory Social Isolation (ASPO) national government decree, impacted on the processes of identifying theaters as workers, their collective organization to face the emergency and their relations of articulation and demand concerning the State agencies dedicated to the promotion and protection of culture.

The work emerges as part of two parallel and dialogical investigations that address problems surrounding artistic work in La Plata within the last five years. The data that we analyze in this case comes from the fieldwork carried out before the ASPO; from observations and documentary analysis made in this last period, using the technological devices that we have at our disposal, and from a non-probabilistic survey promoted by an organization of Teachers of Self-Managed Performing Arts recently created in the city, whose design, processing and data analysis were in charge of one of the authors of this article. We have put all this into dialogue with the bibliography related to labor issues in general and artistic work in particular.
\end{abstract}

Keywords: artistic work; crisis; cultural policies; La Plata independent theater; precariousness

\title{
1. Introducción
}

La ciudad de La Plata, capital de la provincia de Buenos Aires (Argentina) cuenta con una prolífica actividad artística y cultural gran parte de la cual se da en un circuito que se autodefine como independiente o autogestivo y que se ha identificado en base a la capacidad de producir por fuera de los ámbitos oficiales y de los circuitos comerciales, con escasos recursos económicos.

A partir de la pandemia causada por el COVID 19 y la medida de Aislamiento Social Preventivo y Obligatorio (ASPO) decretada por el gobierno argentino, los teatros y espacios culturales debieron cerrar sus puertas, lo cual afectó de manera directa a los/as artistas escénicos/as independientes. Estos/as se vieron impedidos/as de continuar realizando su actividad o debieron transformarla de un modo drástico para adecuarla a un formato virtual. La situación llevó inevitablemente a un detrimento de las realidades económicas de muchos/as artistas que, tal como describiremos en este artículo, producen fuera de los márgenes del mercado laboral formal. Se puso así en evidencia algo que muchos/as artistas venían denunciando cada vez con más fuerza en los últimos años: el carácter precario e inestable de su actividad como fuente laboral.

En respuesta a esta situación, diversas instituciones orientadas al apoyo del teatro, las artes escénicas o la cultura, pusieron en marcha planes de contingencia para acompañar a los/as artistas en situación de mayor vulnerabilidad. Sin embargo, el alcance de estas medidas fue 
limitado. Esto llevó a los/as artistas de todo el país a buscar vías alternativas para continuar ejerciendo su actividad y a reforzar su organización para brindarse apoyo mutuo y para reclamar al Estado mayor acompañamiento ante esta situación de crisis. ${ }^{3}$ En este trabajo nos enfocaremos en el caso del teatro independiente platense con el objetivo de describir y analizar cómo impactó la crisis producida a partir la pandemia y la consecuente medida de ASPO, en los procesos de identificación de los/as teatristas como trabajadores/as, su organización colectiva para enfrentar la situación de emergencia y sus relaciones de articulación y demanda respecto de los organismos del Estado dedicados a la promoción y protección de la cultura.

Para esto, hemos organizado el artículo de la siguiente manera: en primer lugar, especificaremos las decisiones metodológicas que hemos puesto en juego para su construcción. Luego, recuperaremos algunos antecedentes centrales para comprender el circuito en el que se concentra la mayor parte del teatro platense: el teatro independiente. Seguido a eso, desarrollaremos cómo se organiza el mercado laboral artístico en el teatro de la ciudad de La Plata (durante el contexto previo a la situación de excepción generada por la pandemia, así como el impacto y las transformaciones de sus situaciones económicas y sus estrategias laborales a partir del ASPO). A continuación, analizaremos las estrategias de organización de este colectivo de artistas frente al contexto de crisis centrándonos en la conformación de PAEA una red de Profesorxs de Artes Escénicas Autogestivxs. Esta nos resulta paradigmática por haber nucleado a los actores y las actrices en función de la actividad que constituye, para una porción significativa de este conjunto, su principal fuente de ingresos: la enseñanza de teatro. A partir de este caso, describiremos las relaciones de articulación y demanda que este colectivo de artistas estableció con diferentes instituciones del Estado dedicadas al apoyo y protección de la cultura así como la centralidad que adquirió el entramado socio-comunitario de los/as artistas en esta vinculación. Finalmente presentaremos las conclusiones alcanzadas a partir del análisis del trabajo de campo empírico en diálogo con bibliografía específica sobre los mundos del trabajo en general (Castel, 2012) y artístico en particular (Lorey, 2006), teniendo en cuenta el modo en que se vio afectado el sector en un contexto de crisis y las perspectivas del rol del Estado en tanto agente protector y regulador de sus situaciones de trabajo.

\footnotetext{
3 Recuperamos la noción de crisis que define Mariana Busso (2010) como "momentos de quiebre o ruptura entre una situación conocida, sea de crecimiento o de estabilidad (económica, política, social), y un nuevo escenario teñido por la inestabilidad, los desequilibrios y la incertidumbre.” (p. 127).
} 


\section{Metodología}

Este trabajo surge como parte de dos investigaciones paralelas y en diálogo que abordan problemas en torno al trabajo artístico en La Plata dentro de los últimos cinco años: un trabajo etnográfico sobre los procesos de formación trabajo y autogestión de los/as teatristas platenses realizado por una de las autoras como parte de sus investigaciones doctorales (del Mármol, 2016) y posdoctorales (del Mármol, 2020; del Mármol y Basanta, 2020) y un estudio de las situaciones laborales de actores y actrices de teatro independiente de la ciudad, basado en el análisis cualitativo de encuestas no probabilísticas, observaciones participantes y entrevistas en profundidad realizado por la otra autora en el año 2018 para la elaboración de su tesina de grado (Díaz, 2018) y que actualmente continúa en el marco de su investigación doctoral.

Para este artículo, nos propusimos analizar el problema desde una perspectiva cualitativa teniendo en cuenta el trabajo de campo previo al ASPO y nuevas técnicas implementadas en este último período, utilizando los dispositivos tecnológicos que tenemos a nuestro alcance como instrumentos de recolección de información para la construcción de datos. Realizamos observaciones participantes en encuentros abiertos a todo público (por las plataformas Zoom, Instagram y Youtube) y cerrados (por medio de grupos de Whatsapp o encuentros por Zoom de índole más privada) para poder conocer qué aspectos se discutían en un contexto atravesado por las mediaciones de la virtualidad en tanto artefacto cultural (Hine, 2004). También, incorporamos el análisis documental (Valles, 1997) de anuncios, políticas públicas y reclamos que circulan por redes sociales, medios de comunicación y páginas de organismos institucionales afines a la temática. Para esto hemos recolectado documentos textuales, hipertextuales y multimediales (Orellana Lopez y Cruz Sanchez Gomez, 2006, p. 209) disponibles en internet que nos permitieron realizar un seguimiento detallado y confiable.

Otra fuente importante de información que hemos utilizado en este artículo es una encuesta impulsada por PAEA cuyo diseño, así como el procesamiento y análisis de datos, estuvo a cargo de una de las autoras de este artículo, quién se encontraba asistiendo, en calidad de observadora participante, a las reuniones de este colectivo. Los datos construidos sirvieron al grupo para difundir aquello que consideraban más relevante y presentar un informe a la Secretaría de Cultura de la Municipalidad de La Plata entre otras figuras políticas con quienes fueron articulando. Las encuestas son de carácter no probabilístico ${ }^{4}$ ya que no existen, hasta el día de la fecha, datos certeros de cuál es la población total de profesores/as de teatro en la región. De este modo, el objetivo de la implementación de esta técnica no es generalizar

\footnotetext{
${ }^{4}$ Es decir que no posee representatividad estadística, pero que cuenta con la ventaja de aplicar la técnica con escasos recursos económicos y humanos (Baranger, 2009: 37).
} 
resultados estadísticos sino indagar, en diálogo con las otras técnicas, las percepciones de los sujetos sobre sus condiciones de trabajo. Las encuestas fueron auto-administradas por web (López-Roldán y Fachelli, 2015, p. 15). El instrumento fue elaborado mediante un formulario de Google Forms y distribuido por redes sociales como Facebook, Instagram y WhatsApp entre los días 15 de mayo y 11 de junio de 2020. Las respuestas fueron controladas por la misma persona que las recolectó, procesó y analizó. Así, hemos conseguido los resultados a partir de un total de 141 respuestas válidas de profesores/as de las artes escénicas en La Plata, 2020.

\section{El teatro independiente como modo de producción característico de la escena local}

La mayor parte de la producción teatral de la ciudad de La Plata se concentra en un circuito que se denomina independiente y que tradicionalmente se ha definido como alternativa y por oposición a otros dos modos de producción cultural: la oficial y la comercial. Entendiendo el teatro comercial como aquel cuya realización está a cargo de productoras o empresas privadas que buscan lograr un producto exitoso para las lógicas actuales del mercado capitalista y el teatro oficial como aquel que depende del financiamiento estatal y sus políticas de gestión. Frente a estos dos modos de producción artística, el teatro independiente se define por su carácter autogestivo y por la búsqueda de una autonomía ${ }^{5}$ (tanto a nivel creativo como en sus formas de organización) que lo desligue del tipo de condicionamientos (estéticos, ideológicos, procedimentales) presentes en los otros dos modos de producción. Podemos mencionar también un cuarto tipo de amplia representación en nuestro país, el teatro comunitario, un modo de teatro barrial basado en una política de inclusión (el objetivo que prima es ofrecer la oportunidad de realizar una obra de teatro a mucha gente, sin importar la trayectoria artística, el género, la edad, entre otras), cuyos participantes pueden o no ser teatristas profesionales (Fernández, 2013).

Las particularidades del teatro independiente como modo de producción han sido indagadas por diversos/as autores/as de nuestro país (Marial, 1955; Ordaz, 1957; Bayardo, 1997; Pelletieri, 2006; Mauro, 2011; Dubatti, 2012; Perinelli, 2014; Fukelman, 2017), fundamentalmente a partir del caso porteño, tanto en perspectiva histórica como en clave actual, señalando la importancia de esta modalidad teatral en Argentina e incluso su

\footnotetext{
${ }^{5}$ La autonomía que se proclama es principalmente discursiva ya que, desde los inicios del teatro independiente en la Argentina hasta la actualidad, se han vislumbrado articulaciones existentes con organismos estatales y privados que, al menos en parte, irrumpen con la idea de lo completamente independiente.
} 
expansión hacia otras regiones de latinoamérica (Dubatti, 2012). Estos/as investigadores/as caracterizan al teatro independiente haciendo énfasis ya sea en su intención de oponerse al teatro comercial, como en la de liberarse de cualquier tipo de condicionamiento por parte del Estado. De esta manera, tienden a coincidir en presentarlo como "un teatro donde todos ponían plata [y] nadie sacaba un peso" (Pelletieri en Ciurans, 2004, p. 90) o como un modo de producción en el que "los artistas pagan su propio trabajo o se organizan para conseguir el dinero, ya que no son contratados por nadie que asuma los riesgos económicos del espectáculo" (Fukelman, 2017, p. 302). La naturalización de este rasgo característico ha sido especialmente problematizadas por Karina Mauro (2018) quien señala que los ideales del teatro independiente consolidados durante las primeras etapas de este proyecto funcionaron como factor retardatario en el proceso de construcción de la identidad de los/as artistas escénicos/as como trabajadores/as contribuyendo a "sumir a la problemática laboral del arte en una invisibilidad que aún pesa sobre ella" (p. 206).

Mientras algunos/as de estos/as autores/as (como Dubatti, 2012 o Fukelman, 2013) sostienen la continuidad del teatro independiente en la actualidad, otro conjunto argumenta que el proyecto teatral independiente tiene un fin claro en la década de 1960. Momento en que un gran número de teatristas del circuito independiente se sindicaliza y la Asociación Argentina de Actores (entidad con personería gremial que existe en nuestro país desde 1918) incluye el modo de producción autogestivo, a través de una Reglamentación para Sociedades Accidentales de Trabajo, vigente hasta la actualidad (Bayardo, 1997; Mauro, 2018). Este segundo conjunto de autores/as, prefiere referir a las iniciativas generadas a partir de aquella fecha como teatro alternativo (Perinelli, 2014), autogestivo (Mauro, 2018) u off (Bayardo, 1997), denominaciones que también se encuentran relativamente extendidas entre los/as teatristas de la ciudad de Buenos Aires.

Como hemos desarrollado en trabajos anteriores, en La Plata la denominación independiente continúa teniendo una vigencia notable y la mayor parte de los/as artistas escénicos/as locales (y fundamentalmente el colectivo que disputa por el reconocimiento de su actividad en términos laborales y profesionales) suelen reconocerse a sí mismos como independientes (del Mármol, Magri y Sáez, 2017) ${ }^{6}$. Incluso cuando muchos/as de ellos/as trabajen en instituciones oficiales y cuando la mayor parte desearía obtener de sus obras una ganancia económica mayor, la gran mayoría de los/as teatristas platenses no dudan al reconocerse como parte del

\footnotetext{
${ }^{6}$ Los términos alternativo y autogestivo también son utilizados. El primero de ellos, en algunos casos particulares y minoritarios, como reemplazo de independiente; mientras que el segundo, más frecuente, suele ser utilizado para señalar la pertenencia a un un sector más amplio, el de la producción cultural autogestiva, del que el teatro independiente participa estableciendo relaciones con otras disciplinas artísticas.
} 
teatro independiente siendo este circuito productivo el que garantiza las posibilidades de ejercer la actividad laboral aunque sea en condiciones basadas en la precariedad (Díaz y Henry, 2020). Por otra parte, aún los/as teatristas que trabajan en relación de dependencia con alguna institución oficial, suelen participar también de proyectos desarrollados de manera independiente. De modo que los límites entre lo independiente, lo oficial y lo comercial son, en cierto modo, imprecisos y entre estos ámbitos existen numerosas transacciones, vínculos e intercambios.

\section{Condiciones de trabajo en el ámbito teatral platense}

Según los archivos del Instituto Nacional del Teatro (INT), hasta octubre de 2018, La Plata contaba con 31 salas de teatro independiente registradas, 7 salas de teatros oficiales y 4 salas de teatro comerciales. Sin embargo, ninguna posee elencos estables de actores y actrices. Las salas comerciales (al igual que algunas de las salas municipales) suelen contratar obras y espectáculos producidos en el circuito comercial porteño. No existe en nuestra ciudad un circuito de producción de obras a nivel comercial que permita a los/as artistas recibir ingresos sustantivos de su actividad. En el caso de las salas oficiales, las ofertas laborales para los/as teatristas locales suelen ser bastante esporádicas, no habiendo, en ninguna de ellas, una programación permanente conformada por producciones locales. La oferta de estas salas puede tratarse de obras creadas con anterioridad en el circuito independiente (con lo cual sólamente "se compran las funciones" pero no se paga ni el tiempo ni el trabajo de creación) o de producciones creadas en ese mismo espacio teatral. En esos casos, se suelen ofrecer modos de trabajo por proyecto que pueden implicar contrataciones por períodos de tiempo acotados (generalmente unos dos meses) para la realización de nuevas producciones o incluso la puesta a disposición de espacios e infraestructura para el desarrollo de obras bajo el formato de residencias que no ofrecen ningún tipo de remuneración a los/as artistas participantes. Dado que las salas del Estado pueden ser de dependencia provincial o municipal y que en cada una de ellas se proponen diferentes tipos de proyectos, los arreglos no siempre son idénticos por lo que las formas de pago, los tiempos y los montos varían ampliamente de un caso a otro ${ }^{7}$.

En el caso de las producciones independientes, son los propios elencos quienes se acercan a las salas para solicitar un espacio en la agenda donde poder mostrar su obra. En este caso, la ganancia es un porcentaje determinado, aproximadamente el $70 \%$ de lo recaudado en las entradas (siempre que no se pierda lo invertido en el seguro de sala, un acuerdo por el cual el

\footnotetext{
7 En algunos casos, los pagos son realizados en efectivo y con anterioridad a la finalización de la obra, mientras que en otro, se pagaba por depósito bancario meses después de las funciones siendo habituales los casos en los que los retrasos en los pagos son tales que desatan largos reclamos por parte de los/as artistas.
} 
elenco se compromete a pagar un monto de base equivalente al que la sala recibiría en caso de llenarse una parte importante de las localidades). Por lo general, las salas ofrecen funciones de teatro los fines de semana entre una y tres obras por noche, entre los meses de marzo y diciembre. Estos grupos independientes, suelen consensuar mediante acuerdos de palabra entre los/as integrantes cómo repartir las ganancias (siempre y cuando hayan alcanzado a cubrir todo el dinero invertido por sus miembros). Muchas veces ocurre que la ganancia es tan escasa que, antes de repartirla, deciden reinvertirla en ese proyecto teatral (o alguno nuevo con el mismo grupo). En este contexto, sustentarse económicamente por medio de la actuación o la producción de obras se vuelve muy difícil, a tal punto que, con escasas excepciones, los/as teatristas locales sostienen que en La Plata nadie vive de actuar.

En este sentido, encontramos dos elementos claves que permiten a estos sujetos continuar con su actividad actoral más allá de estas situaciones. Por un lado, que la gran mayoría de los casos viven en situaciones de pluriempleo. Es decir, muchos/as actores y actrices trabajan en otras ramas laborales, a veces relacionadas a la actividad artística, por ejemplo, dando clases de teatro; otras, en sus bordes, vendiendo bebida o comida en eventos realizados en el ámbito cultural; y muchas otras, en actividades por fuera del circuito, por ejemplo, como docentes en áreas no artísticas, comerciantes, investigadores/as, empleados/as administrativos/as, entre muchas otras variantes. Los/as que viven exclusivamente del teatro suelen obtener sus ingresos más estables y significativos enseñando la actividad. Dentro de este conjunto están quienes cuentan con un título oficial de profesor/a de teatro y dan clases en escuelas y quienes lo hacen en talleres privados. Es habitual que, quienes pueden, combinen ambos empleos y articulen diversos tipos de clases y espacios de trabajo.

El otro elemento que permite a los/as teatristas platenses sostener su actividad es el vínculo con políticas culturales que ofrecen entidades como el Fondo Nacional de las Artes (FNA), el Instituto Nacional del Teatro (INT) y el Consejo Provincial de Teatro Independiente (CPTI). Estas políticas no garantizan necesariamente mejores condiciones laborales para los trabajadores, sino que funcionan como un soporte para garantizar las producciones culturales en el espacio local. Se realizan ofreciendo distintos tipos de becas y subsidios individuales y colectivos para la producción teatral así como premios por medio de concursos que convocan obras de teatro ya constituidas. Para poder acceder a algunas de las becas, subsidios y/o premios, al menos un integrante de cada grupo suele registrarse facturando por monotributo ${ }^{8}$

\footnotetext{
${ }^{8}$ El monotributo es una modalidad para registrar el trabajo de quienes ejercen de manera autónoma e independiente. Esto es regulado desde la Administración Federal de Ingresos Públicos (AFIP) en Argentina. En los casos de elencos teatrales suelen utilizar el monotributo de algún integrante del elenco o, en caso de no contar
} 
su trabajo. El acceso a becas, subsidios y premios no es sencillo, ya que implica la organización de los antecedentes del grupo y/o la obra, la redacción de proyectos y el armado de "carpetas" que incluyen presentaciones escritas y audiovisuales de las propuestas artísticas para las que se piden los apoyos y, en los casos en los que estos son obtenidos, la gestión burocrática de la rendición del dinero gastado. Representa por tanto un trabajo adicional, ligado a la gestión que en algunos casos se terciariza y en otros es asumido por uno o varios miembros del grupo. Otras veces sucede que no hay integrantes del elenco interesados/as en destinar tiempo de trabajo para realizar esa tarea, por lo cual, desisten del pedido de este tipo de apoyos.

Un rasgo importante a destacar, es que el financiamiento que se brinda suele estar destinado exclusivamente a gastos relativos a la producción de las obras y son muy pocos los casos en los que parte del dinero puede destinarse a honorarios de los/as artistas participantes, siendo mayoritarios aquellos en los que esta posibilidad se excluye de modo explícito. No obstante, aunque de modo muy parcial, estos apoyos contribuyen al sostén económico de los/as artistas que los reciben, ya sea de modo directo (en los pocos casos en los que pueden destinarse al pago de honorarios) o indirecto (cuánto permiten una mejor producción de las obras sin necesidad de un desembolso extra de dinero por parte de los/as artistas).

De este modo, ninguna de las formas de ingresos que los/as teatristas platenses obtienen a partir de la producción artística les permite su pleno sostén económico. Sin embargo, para una gran parte de los/as artistas locales, cada uno de estos ingresos acotados y fragmentarios, contribuye a este sostén entramándose con otras actividades laborales. En algunos casos, estas otras actividades incluyen un empleo estable como docente de teatro en instituciones oficiales, en ámbitos de la administración pública ligados a la cultura o en una actividad sin ningún tipo de vinculación con lo artístico. Pero en muchos otros casos, esos otros trabajos se desarrollan también de manera informal ya sea en el ámbito de la cultura (dictado de clases en ámbitos privados del circuito independiente, organización de eventos artísticos, elaboración y oferta de comida y bebida en eventos culturales) o por fuera del mismo.

Frente a estas situaciones, nos planteamos una serie de preguntas: ¿Qué ocurre con la subsistencia de estos/as artistas antes las medidas de ASPO decretadas en Argentina como modo de prevención ante la epidemia del COVID 19? ¿Cómo impacta la crisis generada por la imposibilidad de seguir desarrollando su trabajo en los modos habituales en la percepción

con uno, solicitan un monotributo social para poder facturar. No obstante, dado que muchas de estas becas y subsidios sólo otorgan dinero para la producción, es frecuente que quienes deban facturar no sean los propios miembros del elenco sino los/as terceros/as (técnicos/as, escenógrafos/as, vestuaristas/a, diseñadores/as, comunicadores/as, etc.) a quienes se contrata para la producción. 
de este sector como colectivo de trabajadores/as? ¿Qué procesos de organización se ponen en juego? ¿Cómo es el vínculo con el Estado?

\section{EI trabajo de actores y actrices en condiciones de ASPO}

El año 2020 se ve atravesado por un contexto de pandemia mundial a partir de la propagación del virus COVID 19. En este marco, la noche del 19 de marzo de 2020, el Presidente de la Nación, Alberto Fernández, anunció las nuevas políticas aplicadas a partir del decreto $\mathrm{N}^{\circ}$ 297/2020: el Aislamiento Social, Preventivo y Obligatorio (ASPO) en todo el país. Esto implicó que las actividades teatrales, entre muchísimas otras, se vean suspendidas. A medida que pasaba el tiempo, se fueron permitiendo cada vez más actividades consideradas esenciales, es decir, aquellas que contaban con un permiso para circular debido a las necesidades de su actividad. Estos permisos fueron variando por regiones, pero la ciudad de La Plata fue una de las localidades más afectadas en términos de cantidad de contagios, de modo que todas las actividades culturales que implican encuentros presenciales continuaron suspendidas.

Este contexto fue catalogado por un gran número de artistas en todo el país como una situación crítica de emergencia cultural ${ }^{9}$, impulsando diversos procesos de organización. En la ciudad de La Plata pudimos observar el fortalecimiento de redes y colectivos ya existentes, como es el caso de la Red Multicultural La Plata ${ }^{10}$ (que reúne a representantes de espacios culturales autogestivos y de colectivos de distintas disciplinas o actividades artísticas) así como la conformación de nuevas organizaciones como la de Profesorxs de Artes Escénicas Autogestivxs (PAEA) a la que nos referiremos más extensamente en el apartado siguiente.

Mientras tanto, distintas entidades estatales fueron otorgando en los meses de ASPO, una serie de políticas públicas focalizadas a artistas, muchas veces, priorizando los casos que se encontraran en situaciones de mayor vulnerabilidad. Desde el INT, se anunció el Plan de Preservación Operativa de Elencos, Salas y Teatristas Argentinos (PODESTA), que intentó inicialmente dar respuesta inmediata a la situación crítica de aquellos/as que habían sido

\footnotetext{
${ }^{9}$ Durante el tiempo de elaboración de este artículo fue presentado el Consejo Deliberante de la Municipalidad de La Plata un proyecto de Ordenanza Municipal elaborado e impulsado por las organizaciones locales de artistas y acompañado por concejales/as del Frente de Todxs. Sin embargo el bloque oficialista del gobierno municipal se opuso a su tratamiento y lo derivó para su estudio en diferentes comisiones ligadas al deporte y la cultura.

${ }^{10}$ La Red Multicultural es una organización que comenzó a funcionar hace varios años, reuniendo inicialmente a organizaciones de espacios culturales, murgas y carnavales. A lo largo del proceso de organización generado durante el contexto de pandemia se convirtió en el espacio articulador de muchas otras organizaciones de artistas tales como ACIADIP (Asociación de Coreógrafos/as, Intérpretes y Afines a la Danza Platense), PAEA (Profesores/as de Artes Escénicas Autogestivos/as), Cucha! Músicos/as Produciendo y representantes de SADEM (Sindicato Argentino de Músicos/as).
} 
seleccionados/as recientemente en convocatorias de concursos y becas del INT. Pero como dijimos anteriormente, no todos/as los/as artistas solicitan estos apoyos y un conjunto aún más restringido accede a ellos, por eso se anunció una segunda etapa que permitiera llegar a más artistas. En este marco, se propuso una serie de concursos nacionales donde se seleccionaron 250 proyectos virtuales y cuyo premio era una bonificación de $\$ 10.000 .{ }^{11}$ Finalmente, se lanzó una tercera etapa que propuso nuevas líneas de ayudas regionales a partir de convocatorias específicas en las provincias de Tierra del Fuego, Santa Cruz, Chubut, Río Negro, Neuquén y La Pampa.

Por otra parte, el FNA hizo público un beneficio llamado "Beca Sostener Cultura I y II" dirigida a artistas (no solo de teatro), cuya economía ha sido notoriamente afectada por el contexto crítico. En la primera etapa, se adjudicaron $\$ 20.000$ a cada persona seleccionada, mientras que en la segunda etapa se adjudicaron $\$ 30.000$ a los/as seleccionados/as, teniendo prioridad las personas en situación de mayor vulnerabilidad económica.

El Ministerio de Producción, Ciencia e Innovación Tecnológica de la Provincia de Buenos Aires lanzó el concurso "Mi vida en cuarentena", donde se invitó a artistas y productores/as de la provincia (que hayan desarrollado actividades en un centro o espacio cultural bonaerense en los últimos doce meses) a enviar una producción virtual. Entre los envíos, se seleccionaron 362 beneficiarios $^{12}$ con un aporte económico de $\$ 8.000$. A su vez, 22 de esos beneficiarios ${ }^{13}$, fueron destacados y sus producciones concursaron por la plataforma Youtube, recibiendo \$10.000 el/la ganador/a de cada categoría artística.

El CPTI lanzó una convocatoria de subsidios en tres líneas: investigación, funcionamiento de salas y producción artística digital, destinadas especialmente para el contexto de emergencia sanitaria.

Por último, algunas organizaciones (con o sin personería jurídica) como la Asociación Argentina de Actores (AAA) ${ }^{14}$ y PAEA, entre otras, se ocupan de gestionar, recibir y repartir bolsones de alimentos para afrontar la emergencia del momento. También el INT, como parte de su plan de contingencia, distribuyó este tipo de bolsones a los elencos que habían sido beneficiarios de ayudas económicas solicitando explícitamente la "distribución cooperativa y solidaria" de estos apoyos (así como de los monetarios) "entre todes les integrantes de cada

\footnotetext{
${ }^{11}$ Esto es, un equivalente aproximado a 140 USD al valor (en pesos argentinos) del dólar en ese momento.

${ }^{12}$ Entre los/as seleccionados/as, cincuenta y cinco son de la ciudad de La Plata, once de ellos/as de la categoría de Artes escénicas.

${ }^{13}$ Seis de los/as seleccionados/as son de la ciudad de La Plata. Uno de ellos/as de la categoría de Artes escénicas

${ }^{14} \mathrm{Se}$ trata del sindicato con personería gremial de los/as trabajadores/as de la actuación en Argentina. La misma, adhiere a la Central de Trabajadores Argentina (CTA) y tiene curso legal desde el año 1919. Su sede central funciona en CABA.
} 
proyecto. Hacerlo de manera responsable y equitativa, poniendo énfasis en asistir a las y los compañeros en situación de mayor vulnerabilidad que pertenecen a sectores de la economía informal". ${ }^{15}$ Como señalan Camezzana, Cappaso, Mora y Sáez (2020) en un trabajo recientemente publicado sobre la situación de las artes escénicas bonaerenses en el contexto del ASPO, esta solicitud resulta interesante ya que implica un reconocimiento institucional de la existencia de "redes de organización en torno a la creación que exceden la concreción de la obra y podrían convocarse en esta circunstancia para viabilizar otras acciones en cogestión" (p.5).

Resulta significativo el modo en que conviven, en este conjunto tan diverso de medidas, lógicas de emergencia orientadas a apoyar a aquellos/as artistas que se encuentran en situaciones más vulnerables con otras, de concurso orientadas a premiar y financiar la producción artística. Es decir, que aún cuando la gran mayoría de estos programas se presentan como acciones que conducen apoyar a un sector que se encuentra en una situación económica crítica, muchas de ellas mantienen criterios de índole meritocrático al solicitar a los/as artistas el envío de producciones o proyectos que luego serán seleccionados. También resulta llamativo que algunas de estas líneas de apoyo creadas específicamente para dar respuesta a la situación de emergencia en la que se encuentran los/as artistas independientes en el contexto de ASPO, indiquen explícitamente que el dinero otorgado no podrá ser utilizado en el pago de sueldos a los/as integrantes del proyecto. Esta diversidad de lógicas que conviven en los programas de apoyo da cuenta de la multiplicidad de sentidos, sobre el trabajo artístico y sobre el perfil socio-laboral de quienes lo desarrollan, que se encuentran vigentes en estas instituciones.

Lo cierto es que más allá de los esfuerzos de cada una de estas instituciones en generar políticas de contención y de la importancia que estos apoyos han tenido para la comunidad artística independiente, sus resultados parecen insuficientes en momentos críticos, tal como se evidenciará con datos de la encuesta que compartiremos en las próximas páginas.

En este contexto surgen dos cuestiones fundamentales: por un lado, se agudizan los reclamos al Estado (provincial y, sobre todo, municipal) por el reconocimiento y apoyo específico hacia un sector, el de la producción cultural independiente o autogestiva, que considera que su actividad representa la mayor parte de la oferta cultural platense y constituye un rasgo fundamental de la ciudad. Al mismo tiempo, se pone en evidencia (tanto para las organizaciones de artistas como para los organismos del Estado a los que se reclaman apoyos)

15 Recuperado el 31 de agosto de 2020 del sitio oficial del Ministerio de Cultura de la Nación: https://www.cultura.gob.ar/plan-podesta-para-potenciar-al-teatro-independiente-argentino-8868/ 
la necesidad de un registro certero de la población que compone este sector, que permita ponderar la magnitud de este colectivo y las situaciones socio-laborales de sus integrantes. Esto impulsa una serie de relevamientos (con grados de sistematicidad muy disímiles) impulsados por los colectivos y organizaciones de artistas, muchos de los cuales terminan siendo la base para la aplicación de algunas de las políticas de ayuda alimentaria implementadas por organismos del Estado, poniendo en juego mecanismos de articulación entre el Estado y el territorio que han sido descritos para otros colectivos sociales.

Por otro lado, surgen espacios de debate interno en los que se busca discutir las identificaciones de los/as artistas como trabajadores/as de la cultura y construir estrategias colectivas para seguir desarrollando la actividad en este contexto. Más allá del acuerdo generalizado sobre las dificultades para pensar el quehacer teatral sin el encuentro presencial, la extensa duración de la situación de ASPO en nuestra ciudad que ya lleva alrededor de siete meses para los/as trabajadores/as y la repercusión de esta política en las situaciones económicas y productivas de los/as artistas escénicos/as, impulsaron la búsqueda de alternativas que les permitieran mantener algunas de sus fuentes de ingresos y dar continuidad a su tarea.

Así, un tiempo después del primer impacto comenzaron a circular registros audiovisuales de obras realizadas previamente, nuevas creaciones adaptadas especialmente para ser transmitidas por medios virtuales, ciclos de charlas por medio de redes sociales e incluso eventos con números en vivo. Muchas de estas actividades se ofrecieron de manera gratuita o a cambio de colaboraciones voluntarias a modo de "gorras virtuales". Sin embargo, las propuestas que más rápidamente buscaron adecuarse a formatos online y que en mayor medida permitieron seguir sosteniendo algún ingreso a los/as artistas en este contexto de excepción fueron aquellas ligadas a la enseñanza de estas prácticas.

De este modo, así como señalamos que en la situación previa al ASPO quienes vivían exclusivamente de la actividad teatral, solían obtener sus ingresos más estables y significativos de la docencia, fue también esta actividad la que permitió un horizonte de mayor continuidad laboral a los/as artistas. Sin embargo, mientras que aquellos/as que desarrollan esta actividad en instituciones formales contaron con una estructura institucional que acompañó los procesos de adecuación y garantizó la continuidad en el ingreso, para quienes desarrollaban la mayor parte de esta actividad de manera informal, por medio de talleres y seminarios privados en salas independientes, estos procesos implicaron estrategias de organización autónoma que no todos/as tuvieron las mismas posibilidades resolver. 
Fue en este contexto, que surgió PAEA, el colectivo de Profesorxs de Artes Escénicas Autogestivxs de La Plata, Berisso y Ensenada ${ }^{16}$, como una estrategia de organización de los/as artistas para visibilizarse como sector, articular demandas al Estado en conjunto con otros colectivos del circuito cultural autogestivo e intercambiar ideas y recursos para la enseñanza de las artes escénicas por medio de la virtualidad.

\section{Una nueva organización de teatristas}

Según relatan sus representantes, la idea de conformar una organización de profesores/as autogestivos/as de artes escénicas surgió a partir de conocer una experiencia análoga (la de los/as Profesorxs de Teatro Independiente -PIT- que comenzó a gestarse en la Ciudad Autónoma de Buenos Aires y a la que se sumaron docentes de otras localidades del Área Metropolitana de Buenos Aires) a partir de la cual se emprendió la construcción de una organización similar a nivel local. En este marco, los/as profesores/as platenses que impulsaron esta idea, empezaron a conversar por redes sociales y a generar un espacio de encuentro virtual al que invitaron a sumarse no sólo a docentes de teatro, sino también de danza y artes del circo y no sólo a quienes se radicaran o ejercieran su actividad en La Plata sino también a quienes lo hicieran en las localidades vecinas de Berrisso y Ensenada. En primer lugar, armaron un grupo de Whatsapp donde, a medida que se sumaba gente, convocaban a las asambleas semanales que empezaron a diagramar por medio de la plataforma Zoom. Ese encuentro virtual sirvió para organizarse como colectivo, para detectar casos de extrema vulnerabilidad económica y para conocerse.

Esto último es fundamental ya que, aún cuando el sector cultural independiente platense se encuentra atravesado por múltiples vínculos de colaboración y reciprocidad que dan sostén material y afectivo a la creación de muchos proyectos artísticos (Lopez, 2015; del Mármol, 2016 y 2020a), e incluso cuando existen en la historia de este colectivo numerosos antecedentes de organización y resistencia política, los lazos que articulan a estos/as artistas en tanto trabajadores/as aún son endebles. Por otra parte, la cantidad de docentes y de espacios en los que estos/as se forman y ejercen su actividad se ha vuelto tan grande en las últimas décadas, que es frecuente que quienes no han compartido proyectos específicos no se conozcan entre sí, y el espacio convocado por PAEA permitió avanzar en este sentido.

Así, aunque hay colaboraciones y encuentros que sostienen en gran medida la producción de este sector, aún cuando en los últimos años la preocupación de este colectivo por definir su

\footnotetext{
${ }^{16}$ Berisso y Ensenada son dos municipios linderos a La Plata y entre sí.
} 
práctica en términos laborales comenzó a ser un tema recurrente al interior del mismo, esto no ha garantizado un avance significativo hacia una articulación sindical que permita incluir a una porción mayoritaria de estos/as trabajadores/as. Por eso, en un marco donde su trabajo es alterado y, en algunos casos, obstaculizado, surge la necesidad de generar nuevos espacios de encuentro y reflexión sobre sus condiciones de trabajo.

Como acabamos de mencionar, no se trata de la primera vez que los/as artistas escénicos/as platenses se organizan colectivamente. Por el contrario, existen importantes antecedentes de este tipo de organización, cuyos hitos más significativos suelen coincidir con momentos de crisis políticas, sociales y/o económicas. Tanto en los relatos que hemos escuchado en nuestros trabajos de campo como en las publicaciones de colegas de nuestra ciudad tres momentos resaltan en este sentido: la salida de la dictadura militar, los años posteriores a la crisis del 2001 y el retorno del neoliberalismo a finales del año 2015.

El período abarcado por los últimos dos años de la dictadura militar y los primeros años de la recuperación democrática (Radice y Di Sarli, 2008) suele ser recordado como un tiempo en el que la comunidad teatral platense se reunió para rearmar todo lo que había sido desarticulado o silenciado durante la dictadura. En palabras de un entrevistado, "en esa época en La Plata nos conocíamos todos, nos reuníamos todos, debatíamos todos (...) no era solamente hacer teatro, era vincularte con otras organizaciones, sindicatos que se estaban armando, centros de estudiantes destruidos que se volvían a armar" (Aroza, en del Mármol, 2015, p.24). Destaca en este período la organización, en 1982 del Primer Encuentro del Espectáculo Platense (una suerte de versión local de los encuentros de Teatro Abierto realizados en CABA, que tuvo su segunda edición al año siguiente) y la recuperación del Coliseo Podestá (una importante sala municipal que había estado clausurada y que planeaba demolerse para la construcción de una playa de estacionamiento).

El período posterior a la crisis del 2001 ha sido caracterizado por autoras como Ana Wortman (2009) y Andrea Giunta (2009) como un tiempo en el que diversos proyectos artísticoculturales buscaron recuperar la organización colectiva y los espacios de encuentro perdidos durante la década neoliberal. Varios trabajos enfocados en la ciudad de La Plata (Gonzales Canosa, 2011; Valente, 2019; Zarauza, 2019), coinciden con esta caracterización y destacan el rol de los espacios culturales autogestionados en estos procesos.

Finalmente, entre fines de 2015 y comienzos de 2016, ante el triunfo de la Alianza Cambiemos a nivel nacional, provincial y municipal y a partir de la amenaza de clausura de centros culturales, los/as artistas platenses comenzaron a reunirse en una organización llamada TOC que realizaba reuniones periódicas, de artistas organizados/as por áreas 
(espacios culturales, visuales, teatro, música, entre otras) y asambleas generales. La organización centró sus objetivos en establecer una articulación interna del sector y buscar canales de diálogo con las autoridades municipales para garantizar la posibilidad de seguir realizando su tarea sin restricciones. Sin embargo, a los pocos meses de su creación su actividad comenzó a mermar diluyéndose hacia fines de 2016 (Pesco, 2019).

Todos estos procesos tienen numerosos puntos en común con el caso que nos encontramos relatando y, al mismo tiempo, algunas diferencias que nos parece interesante destacar. En todos los casos se trata de procesos de organización que adquieren un carácter muy intenso en momentos de crisis y que generan una sensación de articulación muy fuerte de toda la comunidad de artistas, sin embargo, no siempre tienen continuidad. Si bien el objetivo de defender los espacios de trabajo ${ }^{17}$ ha estado presente de algún modo en todos estos momentos, en cierto modo ha primado la defensa de lo colectivo (espacios culturales municipales o autogestionados, posibilidad de construir cultura, defensa del espacio público para la producción artística) y la garantía de derechos laborales individuales ha sido un tema de escasa o nula presencia en la discusión.

En las discusiones que atraviesan la organización de PAEA así como su articulación con otras organizaciones en la Red Multicultural, la defensa de lo común (la producción artística y cultural autogestiva de la ciudad de La Plata, los espacios culturales como sedes de esta actividad) sigue siendo un argumento central en los reclamos al Estado y en el discurso mediante el que se busca visibilizar y legitimar este reclamo. Aún así, encontramos que en esta ocasión, los/as trabajadores/as emergen con mayor presencia como sujetos de dichas demandas. El hecho de que la agrupación convoque a nuclearse a los/as profesores/as poniendo la ocupación de la cual la mayor parte de estos/as artistas obtienen (en condiciones regulares) sus ingresos más estables significativos por delante de su identidad como teatristas, cirqueros/as o bailarines/as es un dato interesante en este sentido (aunque esto no implique desentenderse de sus identidades como artistas). También lo es el interés por la situación sociolaboral de profesores/as y artistas escénicos/as que se puso de manifiesto a partir de las encuestas impulsadas por PAEA y la Red Multicultural. De este modo, aunque la protección y regulación de los espacios (o de los fondos comunes) sigue ocupando un lugar muy

\footnotetext{
${ }^{17}$ En el caso del auge de los centros culturales autogestionados en el período posterior al 2001 existen opiniones contrarias respecto del rol de estos como espacios de trabajo. Si bien autoras como Julieta Infantino (2011) y Denisse Osswald (2009) han remarcado esta función, destacando la preocupación de los/as artistas por hacer de su práctica un medio de vida; otras como como Ana Wortman (2009) o Andrea Giunta (2009) han remarcado que el interés principal de estas propuestas culturales no estaba puesto en la ganancia económica sino en la apuesta política colectiva. La investigadora platense Delfina Zarauza (2019) ha señalado, a partir de un estudio etnográfico en un centro cultural de gran relevancia en nuestra ciudad, cómo estos sentidos contrapuestos aún tensionan entre sí dificultando la demanda de los/as artistas que allí participan por sus condiciones laborales.
} 
importante, la profundidad del contexto crítico generado a partir de la pandemia parece haber dado otro lugar a la preocupación por las situaciones individuales y las condiciones laborales de los/as trabajadores/as, procesos que, no obstante, aún se encuentran en ciernes.

Volviendo a la descripción de PAEA, podríamos pensar las actividades realizadas hasta el momento a partir de tres ejes, que representan tres conjuntos de necesidades: la de conocerse e identificar en qué situaciones estaban y cómo les había afectado la crisis; la de visibilizarse como sector (ante la sociedad y el Estado) y articular demandas en conjunto con otras organizaciones; y la de intercambiar recursos y estrategias para dar continuidad a su tarea por medios virtuales. En función de esto, se llevan a cabo diferentes conjuntos de acciones, impulsadas por comisiones de trabajo y definidas en asambleas virtuales semanales.

Uno de los temas de intercambio que comenzó a darse en estos encuentros tuvo que ver con la socialización de estrategias didácticas para enseñar actuación por medio de la virtualidad. Estos intercambios, que dieron lugar a un recursero colectivo, resultaron un importante apoyo para que muchos/as compañeros/as, que se encontraban menos familiarizados/as con la tecnología o que no podían imaginar cómo encarar la enseñanza de las artes escénicas en ausencia del encuentro presencial, encontraran las herramientas necesarias para adecuar sus clases al medio virtual y retomar así (aunque fuera de modo muy atípico y parcial) una parte de su actividad.

Paralelamente, la asociación comenzó a trabajar en la elaboración de manifiestos que les permitieran posicionarse como asociación y presentarse ante sus colegas ${ }^{18}$; notas de prensa (en medios radiales y escritos) orientadas a exponer su situación ante la ciudadanía y diálogos con las autoridades de los municipios en los que los/as participantes de la agrupación radican sus actividades. Por estas distintas vías, los/as integrantes de PAEA buscaron visibilizar la situación de extrema vulnerabilidad del sector de las artes escénicas independientes y presentar al sector autogestivo como "el pulmón"19 de la producción cultural local.

Otra de las acciones llevadas adelante por el grupo, fue la gestión de bolsones de alimentos conseguidos por medio de la articulación con representantes de los municipios de Berisso y

\footnotetext{
${ }^{18}$ Otra de las acciones realizadas para dar visibilidad a las actividades de la asociación fue un evento virtual, que llamaron Profesorazo (siguiendo la misma lógica de denominación que los Culturazos organizados por la Red Multicultural La Plata, con la cual PAEA articula) que se propuso difundir quiénes integraban esta agrupación y compartir de modo más abierto algunas de las ideas y recursos intercambiados en los espacios de encuentro internos del grupo. (Registro disponible en https://tinyurl.com/profesorazo).

${ }^{19} \mathrm{Al}$ final del manifiesto publicado en la cuenta oficial de PAEA por Instagram y Facebook entre los días 17 y 22 de mayo sus integrantes anunciaban: "Si el pulmón del teatro independiente de la ciudad dejara de funcionar, todxs nosotrxs, profesoras y profesores, alumnxs, actricxs y actorxs, bailarinxs, payasxs, técnicxs, diseñadorxs, boleterxs y espectadorxs, estaríamos en peligro de extinción. Si ese pulmón se apaga, nuestro teatro independiente muere. No permitamos que esto suceda. El teatro independiente no puede dejar de respirar".
} 
Ensenada. Según nos relataron desde el espacio, luego del diagnóstico de que una cantidad creciente de compañeros/as del sector se encontraban con dificultades para cubrir sus necesidades alimentarias básicas, representantes de PAEA acudieron a los distintos municipios para conseguir algún tipo de apoyo, encontrando respuesta en los de Berisso y Ensenada mas no en el de La Plata. Conseguida esta articulación comenzaron a hacerse cargo de recibir y repartir los bolsones a una lista de personas que a mediados del mes de agosto reunía a 107 colegas pero, según nos informaron, continuaba abierta para sumar nuevos/as inscriptos/as. Así, esta nueva organización sin personería jurídica y gestada hace apenas unos meses, funciona como entidad articuladora entre la política pública estatal en respuesta a la emergencia alimentaria sucedida de la sanitaria y las personas que necesitan acceder a ella.

De este modo, PAEA puso en juego al mismo tiempo, formas de articulación conocidas junto a otras novedosas para este colectivo. Formas conocidas ya que se anclan en propuestas de colaboración e intercambio colectivo, basados en lazos de afinidad preexistentes y en nuevos vínculos que se construyen mediante la cooperación en un proyecto compartido pero a su vez novedosas ya que implicaron pensarse como colectivo de trabajadores/as y profundizar las demandas y los modos de articulación con el Estado.

Sin embargo, para poder avanzar en este sentido y fortalecer esta identificación como trabajadores/as tanto al interior del propio colectivo como en sus diálogos con el Estado, era necesario tener datos más precisos acerca de la situación de este sector antes y durante el ASPO. Fue por eso que, al poco tiempo de comenzar a reunirse se puso de manifiesto la necesidad de hacer un relevamiento que permitiera contribuir a su caracterización y se distribuyó una encuesta ${ }^{20}$ que buscaba relevar información sobre sus condiciones sociolaborales, encontrando los siguientes resultados:

En relación a la modalidad de contratación (Gráfico 1), encontramos que un $72 \%$ de los/as encuestados/as declararon estar ejerciendo su trabajo en situaciones de no registro. Esto, en principio, permite comprender la necesidad del Estado por articular con las organizaciones territoriales en pos de llegar a una serie de trabajadores/as que se han visto limitados u obstaculizados en ejercer su trabajo desconociendo cuántos y quiénes son.

\footnotetext{
${ }^{20}$ Se trata, como se explica en la sección metodológica de este artículo, de una encuesta no probabilística orientada a relevar las percepciones de los sujetos sobre sus condiciones de trabajo.
} 


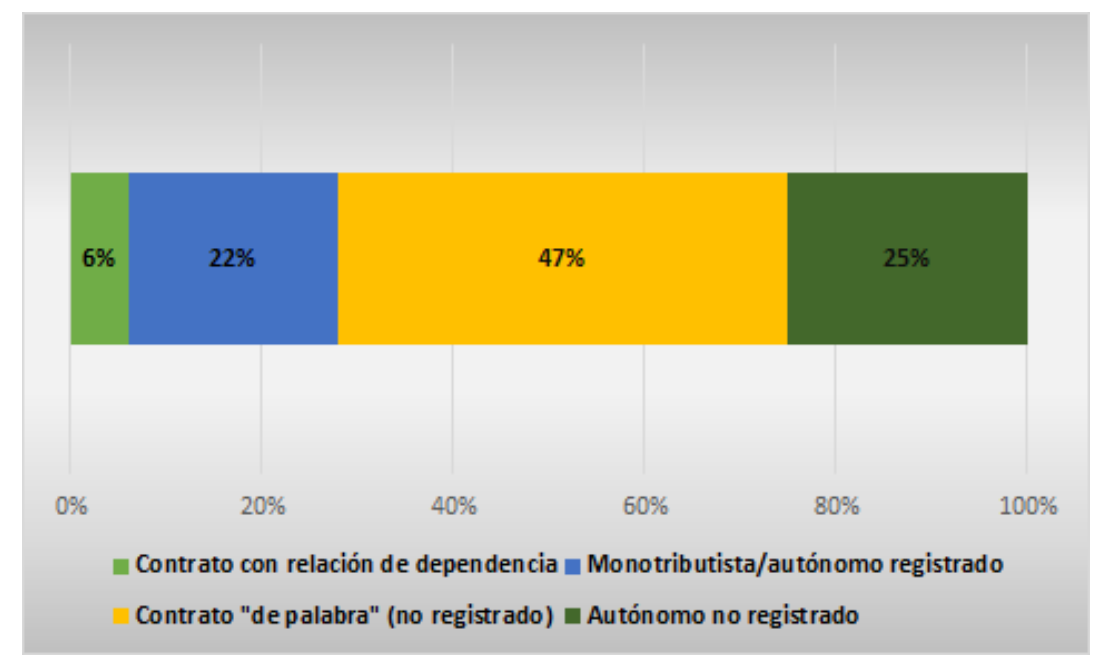

Gráfico 1: Modalidad de trabajo de profesores/as de las artes escénicas antes del ASPO (La Plata, 2020). Fuente: elaboración propia.

De esta manera, también nos interesaba indagar las protecciones que tienen estos/as trabajadores/as que ejercen mayoritariamente fuera de los márgenes de la formalidad. Respecto de este punto encontramos que un poco menos de la mitad de los casos encuestados/as (prácticamente un 43\%) no posee cobertura médica (Gráfico 2). Este dato no es menor siendo que el relevamiento fue realizado en un mes cercano al invierno, en un contexto de pandemia mundial (atravesada por una emergencia sanitaria institucionalmente declarada).

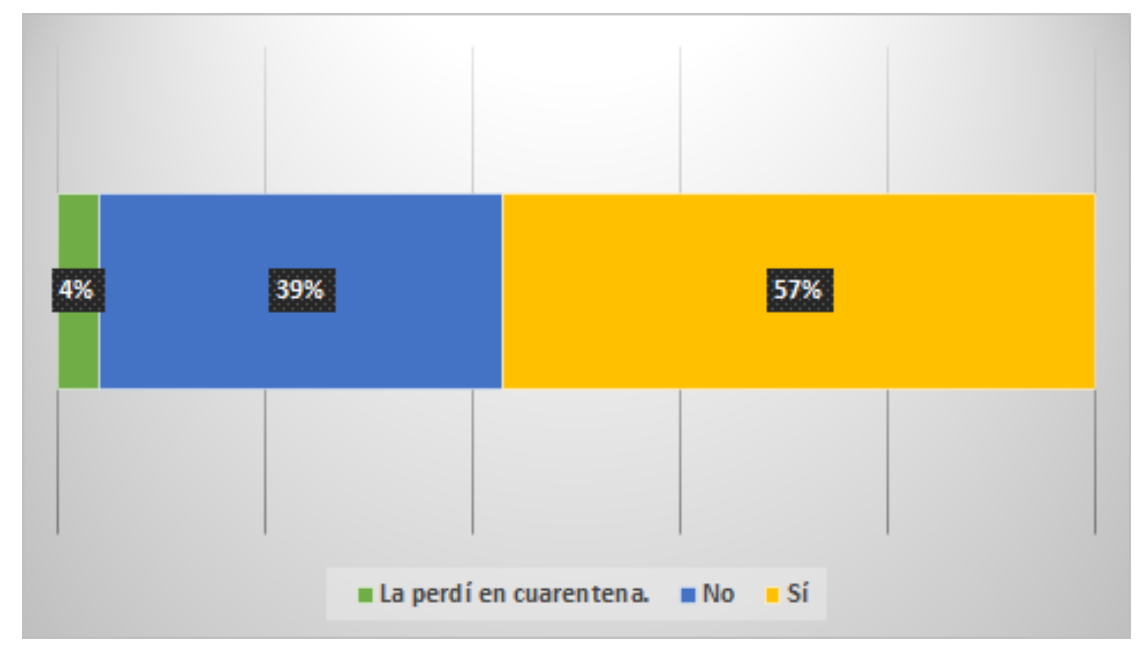

Gráfico 2: Posesión de cobertura médica de profesores/as de las artes escénicas (La Plata, 2020).

Fuente: elaboración propia.

En lo que respecta al perfil etario de los/as encuestados, así como a su grado de formación, el $79 \%$ tiene entre 30 y 49 años y están altamente formados/as (el 87\% cursa o han terminado estudios de ciclo superior). Estos sujetos trabajaban principalmente fuera de los márgenes de la formalidad laboral y se han visto limitados/as en continuar su actividad dado el ASPO. 
La encuesta fue realizada, como se ha dicho anteriormente, durante el mes de junio (habiendo pasado los primeros tres meses de ASPO). En muchos casos, impedidos o imposibilitados a continuar ejerciendo su trabajo (de hecho, al momento de resolver la encuesta solo el 53\% estaba dando clases desde la virtualidad y el $65 \%$ de esos casos estaban cobrando un valor de cuota menor respecto a lo que cobraban en la presencialidad). Aun así, apenas el 45\% pudo acceder a becas y subsidios estatales (Gráfico 3).

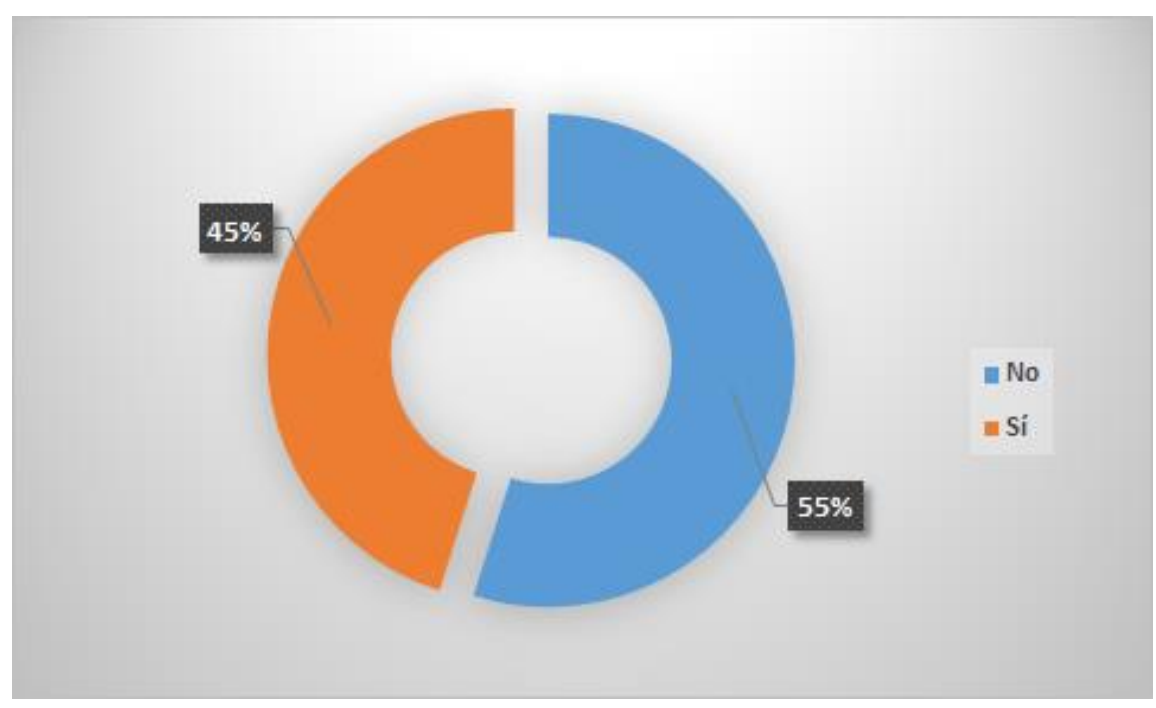

Gráfico 3: Recibo de subsidio estatal durante el período transcurrido de ASPO (La Plata, hasta el 11/06/2020) Fuente: elaboración propia.

Comprendemos entonces que el contexto crítico ha evidenciado y profundizado situaciones de trabajo basadas en la precariedad laboral debido a sus condiciones de informalidad y no registro, al escaso reconocimiento económico y escasa o nula seguridad social, entre otras. Sin embargo, tal como han declarado públicamente los/as miembros de PAEA y de otros colectivos de artistas locales y como hemos señalado nosotras mismas en trabajos anteriores (Díaz, 2020; del Mármol 2020; del Mármol y Basanta, 2020), estas situaciones precarias de trabajo no se iniciaron con la pandemia.

Consideramos que la precariedad laboral en términos contractuales existe históricamente en las artes independientes de la ciudad de La Plata. Sin embargo, esta no siempre ha sido experimentada por los/as artistas en la misma medida, debido a que, según ellos/as, la actividad los/as retribuye con sensaciones de satisfacción y reconocimiento simbólico dentro del mismo campo artístico. De esta manera, el deseo por realizar la actividad artística en ciertos casos ha primado frente al reclamo por mejores condiciones de trabajo. Aun así, en contextos críticos, aparece la necesidad por encontrarse y revisar las situaciones, porque el 
deseo de seguir produciendo se ve imposibilitado y las condiciones de vulnerabilidad de muchos/as de los/as participantes del campo quedan expuestas de un modo más profundo.

En las páginas que siguen retomaremos algunos análisis sobre la precariedad propuestos por autores/as (Castel, 2012; Lorey, 2006 y 2016) que han reflexionado sobre el lugar que ésta ocupa en los modos de trabajo característicos de la contemporaneidad, para continuar pensando desde allí el caso de las artes escénicas platenses.

\section{A modo de cierre: precariedad, crisis y nuevas miradas sobre el Estado}

Uno de los teóricos más importantes de la sociología del trabajo, Robert Castel (2012), ubica a la crisis del petróleo del año 1973 como un momento bisagra de transformación del orden social. A partir de este momento se agiliza el pasaje de una sociedad industrial, basada en el modelo de producción fordista, hacia nuevas regulaciones y vínculos laborales caracterizados por una "dinámica de descolectivización o de reindividualización” que fomenta un ascenso de las incertidumbres para los/as trabajadores/as (p 24). Así, mientras que en el contexto de la sociedad salarial se desarrolla una colectivización de las relaciones de trabajo (que da lugar a una sociedad más cohesionada ya que los individuos están inscritos en colectivos estructurados), a partir del tránsito hacia la modernidad tardía y el capitalismo posindustrial, se imponen vínculos laborales más liberales, exentos de protecciones y regulaciones, que promueven el individualismo y el ascenso de las incertidumbres laborales.

Años más tarde, la teórica alemana Isabell Lorey propone (en palabras de Judith Butler) que "la precariedad no es una condición pasajera o episódica, sino una nueva forma de regulación que caracteriza nuestra época histórica" (en Lorey, 2016, p.13). Además de abordar, en términos generales, el rol de la precariedad en la gubernabilidad neoliberal, la autora dedica parte de su análisis al caso específico del trabajo cultural (Lorey, 2006). Refiere al modo en que los/as productores/as culturales llevan a cabo una precarización "elegida para sí" contribuyendo a convertirse en el tipo de trabajadores/as flexibles que requieren las políticas neoliberales. Sitúa los inicios de esta precarización elegida en los movimientos de los años sesenta en los que los/as artistas buscaron diferenciarse de las condiciones de trabajo normales y de las coacciones que se asociaban a las mismas. Decidir en qué y con quiénes trabajar aunque esto implicara formas más precarias de vida y trabajo ya que consideraban que ésta era la vía para alcanzar una mayor libertad y autonomía. Sin embargo, tal como señala Lorey "son precisamente estas condiciones de vida y trabajo alternativas las que se han convertido, de forma creciente, en las más útiles en términos económicos, puesto que 
favorecen la flexibilidad que exige el mercado de trabajo" (2006: 11) de modo tal que no sólo no han logrado oponerse a la normalización sino que se han vuelto parte de los mecanismos centrales de la gubernamentalidad neoliberal.

De este modo, en línea con el análisis de Castel, la valoración de la independencia y la autonomía que llevó a muchos/as jóvenes de los años ‘60 a rechazar el tipo de trabajo asalariado que habían ejercido sus padres como parte de un conjunto de resistencias a las instituciones y valores establecidos, en la búsqueda de un estilo de vida y una moral más liberales, pregnaron rápidamente el mundo de la empresa y del managment. Así, la crítica progresista a "las coerciones burocráticas y estatales" y a las "regulaciones colectivas y reglamentaciones puntillosas" (Castel, 2012, p. 303) que caracterizaban a la sociedad salarial, se volvió un argumento central de los nuevos modos de trabajo requeridos por el capitalismo neoliberal.

Consideramos que las propuestas teóricas de estos/as autores/as nos brindan interesantes categorías de análisis para pensar el caso platense.

En primer lugar, la identificación de los/as artistas escénicos/as como independientes y la valoración positiva de la autonomía estética y organizativa otorgada por esta posición (aquello a lo que se refieren los/as artistas cuando destacan la importancia de poder elegir con quiénes trabajar, qué tipo de proyectos desarrollar, en qué tiempos, y con qué parámetros vinculares y estéticos) coincide con el tipo de precarización "elegida para si" de la que habla Lorey así como con el rechazo a "las coerciones burocráticas" y "reglamentaciones puntillosas" que menciona Castel.

Esta valoración de la autonomía, así como del carácter placentero y elegido de la actividad desarrollada promueve que, aún cuando se establecen importantes vínculos afectivos con la tarea realizada y con aquellos/as con quienes se emprenden proyectos compartidos, e incluso cuando existe una autopercepción de este conjunto como un colectivo atravesado por la reciprocidad y la cooperación, los procesos de identificación de estos/as actores sociales como trabajadores/as aún están en construcción. Así, más allá de la importancia que ha cobrado en los últimos años la lucha de ciertos sectores de teatristas para que su tarea siga siendo reconocida como un trabajo, gran parte de este conjunto no se encuentra estructurado como colectivo de trabajadores/as ya que son muy pocos los/as que encuentran su actividad artística protegida por una organización sindical ${ }^{21}$ o por legislaciones que regulen y provean garantías

\footnotetext{
${ }^{21}$ En la encuesta realizada, encontramos que apenas el 13\% de los/as encuestados/as se encuentran afiliados a algún sindicato. El 6\% del total, está afiliado a la Asociación Argentina de Actores (AAA) mientras que el 7\% restante se reparten entre otros gremios como la Asociación de Docentes Universitarios La Plata (ADULP),
} 
para el ejercicio de su actividad ${ }^{22}$. En este sentido, desde la óptica de las relaciones laborales, la mayor parte de los/as teatristas platenses ejerce desde la fragmentación, mostrando características afines a la descolectivización e individualización a las que refiere Castel.

Como señalamos en el apartado anterior, esto no significa que no exista organización política de este conjunto. Por el contrario, ya hemos mencionado que existen numerosos antecedentes de articulación y organización de los/as teatristas platenses para la defensa o reconstrucción de un patrimonio compartido (centros culturales, salas teatrales, espacios públicos e incluso el propio lenguaje teatral, como en el caso de la posdictadura) que han alcanzado formas más visibles en momentos de crisis, muchas veces, en relación (o en sintonía) con procesos de organización de artistas de otras localidades. Sin embargo, el foco en la defensa de aquello que se percibe como compartido sumado a la identificación con la informalidad y la flexibilidad que tradicionalmente han caracterizado a la producción artística autogestiva, han llevado a que las organizaciones conformadas no siempre tengan continuidad en el tiempo y en pocos casos aspiren a promover una representación de tipo sindical.

Ahora bien, tal como hemos mencionado, en los últimos años se ha dado una progresiva visibilización de las dimensiones laborales de las prácticas artísticas y la lucha para que la actividad de actores y actrices sea reconocida como un trabajo ha alcanzado a sectores cada vez más numerosos del campo artístico. En este marco, la creencia de que producir por fuera o sin apoyos significativos por parte del Estado tiene la ventaja de permitir un hacer libre de condicionamientos comienza a debilitarse y toma cada vez más fuerza la idea de que es necesaria cierta articulación con el Estado y cierta regulación de la actividad por parte del mismo. Todos estos procesos se vieron acelerados e intensificados por el contexto de crisis generado por una pandemia mundial que limitó y obstaculizó gran parte del trabajo teatral local. Un contexto que, tomando la definición que propone Mariana Busso (2010) para pensar cómo las crisis económicas afectan a los/as trabajadores/as informales, implica "momentos de quiebre o ruptura entre una situación conocida, sea de crecimiento o de estabilidad (económica, política, social), y un nuevo escenario teñido por la inestabilidad, los desequilibrios y la incertidumbre." (p. 127).

Sindicato Unificado de Trabajadores de la Educación de Bs. A.s (SUTEBA), Asociación de Trabajadores de la Universidad Nacional de La Plata (ATULP) y Unión de Trabajadores de Entidades Deportivas y Civiles (UTEDYC).

${ }^{22} \mathrm{Si}$ bien conocemos que existen leyes que definen a la actividad actoral como un trabajo (como la Ley Nacional del Actor $n^{\circ} 27203$ ) no resulta suficiente para regular la heterogeneidad de modalidades de trabajo y contratación descritas en este artículo, ya que la ley citada se orienta exclusivamente a regular contratos laborales por tiempo determinado con relación de dependencia. 
Tal como señala Mariano Llinás (2020) para el caso de los/as artistas porteños/as, la crisis generada por la pandemia puso en cuestión uno de los principales preconceptos dominantes acerca del perfil socio-económico de los/as trabajadores/as del arte y la cultura: que estos/as pertenen, en su totalidad, a clases medias o altas y que por lo tanto, tienen un background económico propio o familiar al que recurrir en caso de que sus ingresos sean insuficientes o, en palabras de Castel (2012) que tienen los soportes suficientes para garantizar su autonomía social. Como menciona Llinás, la cantidad de teatristas que han requerido ayudas alimentarias reveló que esta idea no se correspondía con la situación actual de muchos/as artistas. Volvamos entonces a la propuesta de Castel para pensar esta cuestión desde otras de sus categorías.

El autor propone que en la sociedad contemporánea, la figura clásica del individuo moderno (aquel que lograba alcanzar su independencia social gracias a las garantías de la sociedad salarial) entra en crisis dando lugar a otros dos perfiles de sujetos: los individuos por exceso y los individuos por defecto. ${ }^{23}$ Los individuos por exceso (por exceso de subjetividad va a decir el autor, en referencia a su excesiva preocupación por desarrollar sus aptitudes y su potencial personal y subjetivo) son quienes han desarrollado las posibilidades socioeconómicas que heredaron ${ }^{24}$ para garantizar su autosuficiencia. Estas posibilidades o soportes, que no son solo bienes sino también capitales (Bourdieu, 2007) sociales, culturales, relacionales y simbólicos, les permiten arraigarse "sobre un mantillo social confortable" y "consagrarse a la exploración de su perímetro subjetivo" (Castel, 2012, p. 325), llevando al límite las características de la coyuntura social actual tales como la descolectivización y la desinstitucionalización. En el otro extremo, los individuos por defecto (más allá de las críticas que puedan adjudicarse al término elegido) serían quienes carecen de los recursos necesarios para asumir positivamente su autonomía social, de modo que necesitan de la protección social estatal para autorrealizarse en tanto individuos inmersos en esta sociedad globalizada. Se trata entonces de una diferencia estructural de recursos que garantiza (o no) la posibilidad de alcanzar el status de individuo moderno y que, como afirma Castel al finalizar su libro, cuánto más se profundiza hace más necesaria la intervención y la figura del Estado como agente protector (p. 336).

\footnotetext{
${ }^{23}$ Esta clasificación funciona como tipificación para el análisis social. Esto significa que su función no es discriminar a los sujetos a partir de un señalamiento, sino que nos invita a pensar sobre dos modos de percibir la relación entre los/as ciudadanos/as y el Estado (aunque estos sean irreconocibles en su máxima pureza en la realidad social empírica pero que distinguen). En este sentido, Castel resalta: "Estos perfiles de individuos son como tipos ideales, y habría que dar todo su lugar a las posiciones intermedias. (...) Del mismo modo uno puede ser más o menos un individuo por exceso y más o menos un individuo por defecto” (p. 333).

${ }^{24}$ Retomamos el concepto de la perspectiva bourdiana en relación a las distintas posiciones del campo social en las que nace cada agente (2007).
} 
Tomando entonces esta distinción, los/as teatristas independientes, podrían pensarse como individuos por exceso, en tanto que se trata de sujetos que buscan librarse de las cadenas regulativas siendo autosuficientes, independientes, competentes, capaces de tomar iniciativa, comprometidos/as y creativos/as, las mismas características con las que según Marion Legay (2003), Menger describe a los/as artistas. Sin embargo, observamos que frente a la situación de crisis reclaman al Estado como agente protector y responsable que debe garantizar la posibilidad de seguir creando cultura. Demanda que se agudiza porque, según plantean, en ausencia de ese apoyo la producción cultural independiente corre riesgo de desaparecer. Es decir, que para poder seguir trabajando y produciendo cultura, es necesario un Estado activo que posibilite el acceso a los recursos que, en tanto individuos por defecto no todos/as poseen.

De esta manera, la situación de crisis ligada a la pandemia evidenció, no sólo la importante heterogeneidad socio-laboral de los/as teatristas platenses, sino también las diferencias existentes al interior de este colectivo respecto de los soportes con los que cuentan los/as diferentes integrantes del mismo para desarrollar su actividad de manera autónoma. En este contexto, un amplio conjunto de teatristas (estos sujetos que, como dijimos, vivían del teatro así sea como artistas y/o profesores/as) vio intensificada la necesidad de organizarse como colectivo en situación de precariedad y reclamar al Estado por reconocimiento y protección.

La pandemia intensifica así un conjunto de procesos que venían gestándose de manera acelerada en los últimos años pero que se profundizaron y consolidaron durante esta situación de crisis: la autopercepción de los/as artistas como trabajadores/as; cierto cuestionamiento a la idea de que una mayor independencia respecto del Estado y los marcos institucionales y regulatorios que este impone permite un hacer libre de condicionamientos; y el reclamo para la creación de marcos regulatorios específicos que garanticen la protección de la actividad cultural autogestiva así como la participación de los/as artistas en la toma de decisiones.

Esto no implica una ruptura respecto de la identidad como independientes o autogestivos/as (de hecho esa identificación siempre parece estar presente). Por el contrario, se siguen reivindicando los modos de organización y cierto "saber hacer" propio de este sector y se pide al Estado que lo reconozca en su especificidad. Pero tal vez sí implique cierto cambio en el contenido acerca de lo que esta independencia significa. Fundamentalmente en el tipo de vínculo que se espera establecer respecto del Estado, que ya no se ve como un ámbito del que sólo emanan restricciones y burocracias de las que es mejor mantenerse alejados/as sino como un agente con el que se pretende dialogar e incluso un espacio en el que participar. 
Así, tal como señala Paula Canelo (2020) en un análisis del modo en que la pandemia ha impactado en los vínculos entre la sociedad y el Estado, en los últimos tiempos y para grandes sectores de la sociedad, el Estado parece haber dejado de ser considerado un problema para pasar a ser visto como parte de la solución y, en este contexto de crisis tan extrema, como la única solución posible (p. 20).

Sin dudas esto coincide con la percepción de un gran número de teatristas platenses cuyos procesos de organización en este tiempo se han enfocado, no sólo en desplegar acciones ligadas a la búsqueda autónoma de estrategias de subsistencia sino, en gran medida, al pedido de reconocimiento y apoyo por parte del Estado.

La crisis derivada de la pandemia ha impulsado a este colectivo a profundizar sus vías de organización. Se han multiplicado los espacios de debate en los que seguir afianzando y construyendo su identificación como trabajadores/as. Ha aumentado el conocimiento de las características del sector mediante la implementación de relevamientos que han permitido comenzar a dar cuenta (aunque no de un modo preciso ni acabado) de la cantidad de trabajadores/as involucrados/as en el mismo así como de la situación de informalidad en la que se encuentran gran parte de ellos/as. Estos procesos han permitido a los/as teatristas avanzar en ciertas estrategias de articulación entre entidades del Estado y representantes de las organizaciones de artistas, tanto para la distribución de recursos entre quienes se encuentran en situaciones más vulnerables como para el diseño de proyectos que permitan regulaciones y políticas de mayor alcance para los/as distintos/as integrantes del sector.

Queda, sin embargo, mucho camino por recorrer. Tanto respecto de la autopercepción de los/as teatristas como trabajadores/as y la consolidación de sus organizaciones más allá de las urgencias como de la mirada que los organismos del Estado tienen respecto de la producción artística autogestiva. Esperamos que el intenso movimiento que ha generado esta crisis y el alcance que han tenido estos procesos al interior de la comunidad de las artes escénicas en la ciudad resulte un paso significativo hacia la construcción de un panorama político que promueva mejores condiciones laborales para los/as trabajadores/as del arte y la cultura.

\section{Referencias}

BARANGER, D. (2009), Construcción y análisis de datos: introducción al uso de técnicas cuantitativas en la investigación social. Posadas: Editorial Universitaria de Misiones.

BAYARDO, R. (1997). El teatro "off corrientes": ¿una alternativa estético-cultural?, Tesis de Doctorado. Facultad de Filosofía y Letras, Universidad de Buenos Aires. 
BOURDIEU, P. (2007). El sentido práctico. Buenos Aires: Siglo Veintiuno.

BUSSO, M. (2010). La crisis y el trabajo informal (o de cómo las crisis socio-económicas permean lugares de trabajos "atípicos"). España: Universidad de La Laguna N², pp. 125138.

Disponible

en

https://ri.conicet.gov.ar/bitstream/handle/11336/16342/05\%20Mariana\%20Busso.pdf?sequenc $\mathrm{e}=2 \&$ is Allowed $=\mathrm{y}$

CAMEZZANA, D., CAPASSO, V., MORA, A. y SÁEZ, M. (2020). Las artes escénicas en el contexto del ASPO. Question/Cuestión, 2(66), e470. https://doi.org/10.24215/16696581e470

CANELO, P. (2020). Igualdad, solidaridad y nueva estatalidad . El futuro después de la pandemia. En Grimson, A. (2020) (dir.) El futuro después del COVID-19. Ed. Jefatura de Gabinete de Ministros Argentina. Disponible en https://www.argentina.gob.ar/sites/default/files/el_futuro_despues_del_covid-19.pdf

CASTEL, R. (2012). El ascenso de las incertidumbres. Trabajo, protecciones, estatuto del individuo. Buenos Aires: Fondo de Cultura Económica (FCE).

CIURANS, Enrie (2004). "Entrevista a Osvaldo Pelletieri”. En: Assaig de teatre. Revista de l'associació d'investigació i experimentació teatral. Universidad de Barcelona: Associació d'Investigació i Experimentació Teatra. ISSN 1134-7643.

del MÁRMOL, M. (2015). Discursos y representaciones sobre el cuerpo en el teatro platense del siglo XX. Breve historia de un giro copernicano. Telondefondo. Revista de Teoría y Crítica Teatral, 11(21), 17-33. https://doi.org/10.34096/tdf.n21.1469

del MÁRMOL, M. (2016). Una corporalidad expandida. Cuerpo y afectividad en la formación de los actores y actrices en el circuito teatral independiente de la ciudad de La Plata. Tesis doctoral en Antropología. Facultad de Filosofía y Letras, Universidad de Buenos Aires. Disponible en: http://repositorio.filo.uba.ar/handle/filodigital/4096

del MÁrmOL, M. (2020). Entre el deseo, la amistad y la precarización. Cuadernos De antropología Social, (51). https://doi.org/10.34096/cas.i51.7950

del MÁRMOL, M. y BASANTA, L. (2020). 'El arte no paga'. Reflexiones sobre el trabajo artístico en el contexto del capitalismo contemporáneo. Trabajo y sociedad, (35) 21. https://www.unse.edu.ar/trabajoysociedad/35\%20AA\%20DEL\%20MARMOL\%20Y\%20BA SANTA, \%20El\%20arte\%20no\%20paga.pdf

del MÁRMOL, M.; MAGRI, G. y SÁEZ, M. L. (2017). Acá todos somos independientes. Triangulaciones etnográficas desde la danza contemporánea, la música popular y el teatro en la ciudad de La Plata. Revista de Humanidades y Ciencias Sociales: El Genio Maligno ${ }^{\circ} 20$. Marzo.

DIAZ, J. y HENRY, M. L. (2020). Entre vocación y precarización. Condiciones laborales de actores y actrices en teatro independiente platense. En Busso, M y Perez, P. (2020) (Coord.) El trabajo degradado. Heterogeneidad ocupacional, precarización y nuevas inserciones laborales durante el gobierno de Cambiemos. Ediciones FaHCE-UNLP. (En prensa).

DÍAZ, J. (2020). ¿Para qué estudiamos? Un análisis sobre oportunidades de inserción laboral de estudiantes y egresados/as de la Tecnicatura en Actuación en Escuela de Teatro de La 
Plata. En Revista Latinoamericana de Antropología del Trabajo, $\mathrm{N}^{\circ} 8$, julio/septiembre 2020, ISSN 2591-2755. Disponible en http://www.ceilconicet.gov.ar/ojs/index.php/lat/issue/current/showToc.

DÍAZ, J. (2018). Los Discontinuos : Situaciones laborales de actores y actrices en teatro independiente platense (2018) (Tesis de grado). Presentada en Universidad Nacional de La Plata. Facultad de Humanidades y Ciencias de la Educación para optar al grado de Licenciada en Sociología. Disponible en: http://www.memoria.fahce.unlp.edu.ar/tesis/te.1645/te.1645.pdf

DUBATTI (2012). Cien años de teatro argentino. Desde 1910 a nuestros días. Buenos Aires: Biblos.

FERNÁNDEZ, C. (2013). Antecedentes e historia del teatro comunitario argentino contemporáneo. Los inicios de un movimiento. En AISTHESIS N 54: 147-174.

FUKELMAN, María (2013). "El teatro independiente en los primeros años de la posdictadura". En: La revista del CCC. No 17. Año 6.

FUKELMAN, M. (2017). El concepto de" Teatro independiente" en Buenos Aires, del Teatro del Pueblo al presente teatral: estudio del período 1930-1946. Tesis doctoral. Facultad de Filosofía y Letras, Universidad de Buenos Aires.

GIUNTA, A. (2009). Poscrisis. Arte argentino después de 2001. Siglo XXI: Buenos Aires.

GONZALES CANOSA, M. (2011). Nuevas prácticas y apropiaciones del espacio urbano: El caso del barrio Meridiano $\mathrm{V}^{\mathrm{o}}$ (La Plata) y la Muestra Ambulante del colectivo cultural. Afuera, 6(10), 1-7.

HINE, C. (2004). Etnografía virtual. Editorial UOC: Barcelona.

INFANTINO, J. (2011). Trabajar como artista: Estrategias, prácticas y representaciones del trabajo artístico entre jóvenes artistas circenses. Cuadernos de antropología social, (34), 141163.

LEGAY, M. (2003). Critique de Portrait de l'artiste en travailleur. Métamorphoses du capitalisme de P.M. Menger. Paris: Seuil.

LLINÁS, M. (2020). Nociones de economía bohemia (primera parte). Revista Crisis, (43). Recuperado el 27 de agosto de 2020 de http://www.revistacrisis.com.ar/notas/nociones-deeconomia-bohemia-primera-parte?s=09

LÓPEZ, Matías (2015). "Gestionar espacios, asociar prácticas y apuestas, potenciar políticas estéticas. Apuntes para reflexionar sobre las escenas culturales”. En: Lopez Betancourt [et.al.] (Comp.) Hacer espacio. Circulaciones múltiples entre cuerpos y palabras. La Plata: Club Hem Editores.

LÓPEZ-ROLDÁN, P. y FACHELLI, S. (2015). La encuesta (capítulo II). En P. LópezRoldán y S. Fachelli, Metodología de la Investigación Social Cuantitativa. Bellaterra (Cerdanyola del Vallès): Dipòsit Digital de Documents, Universitat Autònoma de Barcelona. Disponible en: http://ddd.uab.cat/record/163567 
MARIAL, José (1955). El teatro independiente, Buenos Aires, Ediciones Alpe.

MAURO, Karina (2011). La técnica de actuación en Buenos Aires. Elementos para un Modelo de Análisis de la Actuación Teatral a partir del caso porteño. Tesis de doctorado, Facultad de Filosofía y Letras, Universidad de Buenos Aires.

MAURO, Karina (2015). "Reflexiones sobre la asociación, gestión y producción en las artes escénicas a partir del caso porteño". Actas del IV ECART - Encuentro Platense de Investigadores sobre cuerpo en las Artes Escénicas y Performáticas. La Plata: Ecart ediciones. Disponible en http://sedici.unlp.edu.ar/handle/10915/69296

MAURO, K. (2018b). Identidades y apelaciones antagónicas de los trabajadores del espectáculo (1902-1955). telondefondo Revista de Teoría y Crítica teatral, 27, 176-231.

ORDAZ, Luis (1957). "Los teatros independientes" en El teatro en el Río de La Plata - Desde sus orígenes hasta nuestros días, Buenos Aires: Ediciones Leviatán. Pp 199-237.

ORELLANA LÓPEZ, D. M. y CRUZ SÁNCHEZ GÓMEZ, M. (2006). Técnicas de recolección de datos en entornos virtuales más usadas en la investigación cualitativa. En Revista de Investigación Educativa, Vol. 24, n. ${ }^{\circ}$ 1, pp. 205-222.

OSSWALD, D. (2009). Espacios culturales en la Argentina post 2001. La cultura como trabajo. En: Wortman, Entre la política y la gestión de la cultura y el arte. Nuevos actores en la argentina contemporánea. Editorial Eudeba. Buenos Aires.

PELLETIERI, Osvaldo (2006). Teatro del Pueblo: Una utopía concretada. Buenos Aires, Galerna-INT.

PERINELLI, R. (2014). Teatro: de Independiente a Alternativo. Una síntesis del camino del Teatro Independiente argentino hacia la condición de alternativo y otras cuestiones inevitables. Cuaderno $\mathrm{n}^{\circ}$ 50, Centro de Estudios en Diseño y Comunicación.

PESCO, P. (2019). Redes de Espacios Culturales de La Plata. Recorrido Histórico 2015 2018. Ed. Seguir Viaje : La Plata. Disponible en https://drive.google.com/file/d/1COXwZmJEdUImSTtmG6kuRaW5r9P7r6F/view? usp=sharing

RADICE, G. DI SARLI, N. (2008). Micropoéticas teatrales en los comienzos de la democracia: el teatro independiente. Presentado en VI Jornadas Nacionales de Arte en Argentina (La Plata, 2008). Recuperado a partir de http://hdl.handle.net/10915/38937

VALENTE, A. (2019). Tejer redes. Experiencias de coordinación entre espacios culturales autogestionados de la ciudad de La Plata, Argentina. Culturas. Revista de Gestión Cultural, Vol. 6, No, 2, 2019 pp. 46-64.

VALLES, M. (1997). Técnicas cualitativas de investigación social. Reflexión metodológica y práctica profesional. Síntesis: Madrid.

WORTMAN, A. (2009). Entre la política y la gestión de la cultura y el arte. Nuevos actores en la argentina contemporánea. Editorial Eudeba. Buenos Aires. 
ZARAUZA, D. (2019) "Heredar una militancia" Modos en que se transmiten concepciones, valores e ideas en torno a una militancia cultural dentro de las prácticas cotidianas de un colectivo artístico. Ponencia en el III Congreso Latinoamericano de Teoría Social. IIGGUBA. 